HID 48 (2021)

\title{
EL ADICIONARIO AL BECERRO DEL MONASTERIO DE SANTA CLARA DE TORDESILLAS ${ }^{1}$
}

\section{THE ADICIONARIO TO THE CARTULARY OF THE MONASTERY OF SANTA CLARA DE TORDESILLAS}

\author{
Carlos Parra Cítores \\ Universidad de Valladolid \\ Carlos.parra.cit@gmail.com ORCID: https://orcid.org/0000-0002-1945-2600
}

RESUMEN: A medida que crece, tras su fundación, el patrimonio del monasterio de Santa Clara de Tordesillas, lo hace también el volumen documental de su archivo, obligando a crear instrumentos de control que garantizaran la conservación del mismo; uno de estos instrumentos fue el Adicionario de finales del siglo XVIII, escrito para detectar y reducir las pérdidas patrimoniales causadas por la actualización del becerro anterior. El Adicionario es por ello una fuente extraordinaria para estudiar el concepto de archivo y la evolución del patrimonio de las clarisas tordesillanas en el ocaso de la Edad Moderna.

PAlabRas ClaVE: Adicionario; Santa Clara de Tordesillas; Becerro; Archivo; Patrimonio.

ABSTRACT: As it grows, since its founding, the heritage of the Santa Clara Monastery in Tordesillas, it also does the documental volume of its archive, forcing to create control instruments that will ensure its conservation; one of these instruments was the Adicionario of the end of $18^{\text {th }}$ century, written to detect and minimize patrimonial losses caused by the out-of-date of a previous cartulary. The Adicionario is, for these reasons, an extraordinary resource to study the concept of the archive and the evolution of the heritage of the clarisse nuns at the twilight of the Modern Age.

KeYwORDS: Adicionario; Santa Clara of Tordesillas; Cartulary; Archive; Heritage.

Recibido: 7-4-2020; Aceptado: 12-12-2020; Versión definitiva: 17-12-2020

1. Abreviaturas utilizadas: $\mathrm{AHN}=$ Archivo Histórico Nacional; AHPVA $=$ Archivo Histórico Provincial de Valladolid; BNE = Biblioteca Nacional de España.

Copyright: (C) Editorial Universidad de Sevilla. Este es un artículo de acceso abierto distribuido bajo los términos de la licencia de uso y distribución Creative Commons Reconocimiento-NoComercialSinObraDerivada 4.0 (CC BY-NC-ND 4.0) 


\section{INTRODUCCIÓN}

En los últimos años, se ha producido en nuestro país un enriquecedor debate, resultado de una preocupación científica evidente, sobre el concepto y la realidad de los códices diplomáticos conocidos por los diplomatistas españoles como cartularios, tumbos y becerros (o llamados en Francia Trésor des Chartes); formas distintas de referirse a un mismo tipo de libros, si bien entre ellos hay diferencias que es necesario tener en cuenta ${ }^{2}$.

En este artículo, sin embargo, no me centraré en las diferencias tipologías de estos códices, ya conocidas por otra parte, sino en el estudio de un nuevo manuscrito hallado entre los fondos del Archivo Histórico Provincial de Valladolid (en adelante AHPVA): un Adicionario, así es como se autodenomina el documento, de finales del siglo XVIII perteneciente al fondo del monasterio de Santa Clara de Tordesillas $^{3}$ custodiado en el mencionado archivo vallisoletano ${ }^{4}$. Un borrador manuscrito, realizado como paso previo y necesario a la escrituración del códice definitivo, que contiene las apostillas, las añadiduras que complementan y amplían el último de los becerros que se había escrito en el monasterio de Santa Clara. Circunstancia que permite conocer que su realidad patrimonial estaba sufriendo una importante disminución a medida que avanzaba el siglo XVIII.

\section{CONTEXTO HistóRICO. El SIGLO XVIII Y LA POLÍTICA INCORPORACIONISTA}

La creación de un códice diplomático de estas características responde a un marco histórico muy particular que el monasterio de Santa Clara de Tordesillas estaba viviendo a finales del siglo XVIII. Un contexto que queda definido por la combinación de dos elementos estrechamente vinculados entre sí: por un lado, un elemento intrínseco al cenobio, como es la progresiva despreocupación de sus miembros por el cuidado de su archivo y la gestión de su patrimonio. Por otro lado, un elemento extrínseco motivado por el auge de la política incorporacionista de los Borbones que se vivió en toda España durante el siglo XVIII, y sobre todo durante su segunda mitad.

2. Sobre los códices diplomáticos véanse: Mendo Carmona, 2005, pp. 119-137; 2002, pp. $165-$ 189. Suárez González, 2016, pp. 469-476. Sánchez Díez, 2011, pp. 281-352. Sáez, 2005, pp. 37-48. Ruiz Asencio, 1972, pp. 368-370. Keller, 2007, pp. 95-108. Cruz Herranz, 2016, pp. 177-230. Rodríguez Díaz, García Martínez, 2011.

3. Sobre el Real Monasterio de Santa Clara de Tordesillas: Castro, 1989, pp. 79-122. Almagro García, 2005, pp. 2-13. Bahr, 1996, pp. 43-66. García-Frías Checa, 1992. González Herrera, 1965.

4. El hecho de que el manuscrito no se haya encuadernado, ha provocado el desorden de los cuadernos del manuscrito, que en la actualidad se mantiene así en la unidad de instalación del AHPVA: la caja 80 de la Sección Histórica. El Adicionario se encuentra organizado en diferentes cuadernos deslavazados o mal compuestos, y se hace necesaria una ordenación intelectual que explique su razón de ser y la factura del manuscrito. 
Respecto a la despreocupación por el patrimonio del monasterio, lejos de ser un hecho aislado en el siglo XVIII, esto fue en realidad parte de un proceso mucho más complejo, lento pero imparable, que se extiende a lo largo de los siglos XVI y XVII y que conllevó finalmente la pérdida de un vasto número de sus propiedades a finales del siglo XVIII. El archivo del cenobio ${ }^{5}$, por ser el organismo que recogía toda la documentación resultado de sus negocios y actividades, da buena cuenta de este creciente desinterés en el patrimonio del monasterio. De este modo, es interesante observar cómo durante los siglos XIV al XVI la práctica de apeos y deslindes, hallados en el archivo de la institución, reflejan la constante preocupación de las monjas clarisas por conocer y proteger sus heredades ${ }^{6}$. No obstante, la entrada a la Edad Moderna supuso el progresivo abandono de este ejercicio. Tanto es así, que para la segunda mitad del siglo XVIII, el último apeo de dimensiones considerables realizado sobre las propiedades cercanas a Tordesillas se había elaborado un siglo atrás, en el 1641; un trabajo dirigido por el licenciado Gaspar de Baeza de Cianca, corregidor de Tordesillas, y por testimonio de Francisco de Ledesma, escribano del número de esa localidad ${ }^{7}$.

Respecto al elemento extrínseco, este se relaciona como decíamos con la política incorporacionista llevada a cabo por la todavía nueva dinastía borbónica: un movimiento político por el que la monarquía buscó reforzar su posición a través de un proceso de recuperación de las propiedades y regalías que la Corona había ido cediendo a la nobleza tradicional, tanto laica como eclesiástica, a lo largo de los siglos anteriores ${ }^{8}$.

Las consecuencias de esta política incorporacionista marcarán gran parte de la realidad documental vivida en España a lo largo de esta centuria: por un lado, el inicio de un inmenso trabajo intelectual de la documentación presentada a pleito por las instituciones; una labor que como indica Francisco Gimeno Blay, marcará el nacimiento de la Paleografía y la Diplomática Española9. Por otro lado, las consecuencias provocadas por la respuesta proteccionista de las instituciones afectadas. Una reacción que se muestra muy semejante, salvando las distancias temporales, a la que ya habían vivido los señoríos eclesiásticos a lo largo de los siglos XI y XII, un periodo de acoso constante a las instituciones religiosas por parte de la nobleza laica y la monarquía como forma de aumentar su propio poder, y que Carlos Sáez denominó como la rapiña de la nobleza y la realeza ${ }^{10}$. Si bien ahora la nobleza laica estaba igual de amenazada que la eclesiástica, las consecuencias de esta "rapiña" son muy parecidas a las de su homólogo medieval: por un lado, el nacimiento de una mayor preocupación por los archivos como espacios donde se conserva la documentación que prueba sus derechos y propiedades; y por otro

5. Para conocer más sobre el contenido del archivo de Santa Clara de Tordesillas véanse las colecciones diplomáticas de Castro, 1981. González Cristóbal, 1987.

6. Rodríguez Guillén, 2011, pp. 96-99.

7. AHPVA, Sección Histórica, caja 80/28, Capítulo 2.

8. Gimeno Blay, 1986. Gómez Vozmediano, 2015.

9. Gimeno Blay, 1986.

10. Sáez, 2005, pp. 42-43. 
lado, la proliferación de cartularios creados con la intención de defenderse jurídicamente ante estos ataques a su patrimonio.

En el caso de la provincia vallisoletana, son varios los ejemplos que advierten esta reacción proteccionista de las instituciones: por ejemplo, la creación por parte de la Orden Benedictina de unas Nuevas Constituciones durante un Capítulo General realizado en Valladolid en $1706^{11}$, las cuales dedican un apartado exhaustivo a todo lo relacionado con los archivos y los archiveros de los monasterios. O también, la constante actuación de fray Vicente Velázquez de Figueroa ${ }^{12}$, fraile dominico que puso sus conocimientos paleográficos y archivísticos al servicio de varias instituciones de la provincia con el fin de ordenar sus archivos y confeccionar cartularios destinados a la defensa de sus propiedades, destacando algunos como la realización del libro Becerro del convento de San Juan y San Pablo en Peñafiel $^{13}$, o el Becerro destinado al convento de San Pablo en Valladolid, hoy en día conservado en el Archivo Histórico Nacional ${ }^{14}$.

En el caso del monasterio de Santa Clara de Tordesillas, su condición como patronato regio hará que viva esta situación desde un punto de vista particular: más que defenderse de los ataques de la Corona, la institución tendrá que responder ante sus constantes exigencias de mantener controlado su patrimonio; una reclamación que como hemos visto no era cumplida en absoluto por las monjas clarisas, cada vez más despreocupadas por el estado real de sus rentas y propiedades, provocando en consecuencia la constante llegada de visitadores generales al cenobio durante el XVIII con el fin de atacar estas deficiencias en su gestión.

Desde luego, no parece casualidad que fuera en 1707, sólo un año después del establecimiento de la Junta de Incorporación ${ }^{15}$, cuando el visitador Gaspar de Quincoces ordene a las monjas clarisas la misión de reorganizar su archivo al tiempo que se iniciaban los preparativos para proceder con nuevos apeos de las propiedades de esta institución, que no llegaron a realizarse, y se iniciaba el trabajo de un nuevo cartulario que permitiera la defensa legal de este del cenobio. Una basta tarea que fue encomendada a Manuel Queipo de Llano, mayordomo del monasterio, quien aun no habiendo terminado el libro Becerro, lo dará por concluido en 1730 . Y ya en 1776 tendrá lugar una nueva visita, esta vez protagonizada por Fernando de Rojas, miembro del Consejo Real y oidor en la Real Chancillería de Valladolid. Una visita que hoy en día podemos conocer gracias a la conservación en la Biblioteca Nacional de España de un traslado notarial del informe realizado a partir de dicha inspección, con fecha de 3 de septiembre de $1776^{16}$. En sus páginas

11. Fernández Flórez, 1993, pp. 112.

12. Para conocer más a fondo la vida y obra de fray Vicente Velázquez de Figueroa, son de destacar las obras de Martín Postigo, 1982. Chacón Gómez-Monedero, 2006.

13. AHN, Códices, L.1264, "Libro becerro del convento dominico de San Juan y San pablo de Peñafiel" (Valladolid).

14. AHN, Códices, L.1261, "Libro becerro del convento dominico de San Pablo de Valladolid". O véase Sánchez Díez, 2015 para un mayor acercamiento diplomático a los libros becerros conservados en este archivo.

15. Gimeno Blay, 1986, pp. 47-48.

16. BNE, ms. 17840, Papeles varios. Tomo IX, Documento 23. Véase en Castro, 1973. 
se dan a conocer muchos de los mandatos que Fernando de Rojas encomendó al monasterio, los cuales suponen una amplia restructuración de toda la administración de la institución. En lo que respecta al archivo, Fernando de Rojas encomienda una vez más a su mayordomo, en este caso Antonio Antolínez, a su vez escribano público de la localidad, la reorganización del archivo destacando entre sus trabajos la reanudación y conclusión del libro Becerro de Queipo de Llano, cuyo último tomo dedicado a censos, había quedado incompleto.

Pero sobre todo, este informe recoge el mandato para la creación de nuestro Adicionario; una labor encomendada al mayordomo con el fin de actualizar la información contenida en el anterior Becerro de Queipo, que había quedado desactualizado con el paso del tiempo y que ya no representaba la realidad patrimonial ni documental del monasterio de Santa Clara de Tordesillas.

\section{INTERPRETACIÓN DEL ADICIONARIO.}

\section{LA SINGULARIDAD DEL OBJETO DE ESTUDIO}

Desde el punto de vista de la tipología diplomática, el Adicionario parece ajustarse, sin realmente serlo, al grupo de documentos que la Comission Internationale de Diplomatique define como cartularios; es decir:

colección de copias de sus propios documentos, establecida por una persona física o moral, que, en un volumen o más raramente en un rollo, transcribe o hace transcribir integramente, o en ocasiones en forma de extracto, los titulos relativos a sus bienes y a sus derechos y documentos que conciernen a su historia o a su administración, para asegurar su conservación y facilitar su consulta ${ }^{17}$.

Y se acercaría a esta tipología diplomática por el fin que persigue el monasterio al confeccionar dicho manuscrito: complementar y actualizar la información contenida en un códice diplomático anterior, un Becerro del primer tercio del siglo XVIII que tal parece no habría sido actualizado desde el momento de su finalización, volviéndose una obra obsoleta en pocas décadas, como consecuencia de la creación de nuevos documentos, que no se extractaron en sus páginas, la pérdida de otros tantos instrumentos en las dependencias del archivo, y la rápida evolución patrimonial del cenobio tordesillano. Y es precisamente esta desactualización la que haría necesaria la creación de un manuscrito nuevo, con la particularidad de que no nacería con la intención de sustituir a su predecesor sino con el fin de complementarlo.

Las referencias mostradas en el Adicionario y en otra documentación del AHPVA apuntan a que este libro Becerro anterior es el mismo al que hace referencia Santiago Rodríguez Guillén en su tesis doctoral titulada El monasterio de Santa María la Real de Tordesillas (1369-1509): un cartulario elaborado por

17. Cárcel Ortí, 1997, p. 36. 
Manuel Queipo de Llano ${ }^{18}$, hoy en día perdido, pero que podemos conocer de forma indirecta gracias a los índices que se conservan en el AHPVA de cada uno de sus tomos ${ }^{19}$. Según parece, el proyecto original del Becerro estaría repartido en cinco tomos, no obstante, la obra quedaría inconclusa faltando por redactar el quinto tomo dedicado a censos. Mediante la información ofrecida por este Adicionario sobre su libro principal, el Becerro al que complementa, y la información de los índices conservados en el AHPVA, la disposición que tendría el cartulario hoy perdido sería la siguiente:

- Tomo "primero y principal" en el que se tratan los privilegios, derechos y exenciones del monasterio, incluyendo un prólogo con las Órdenes para hacer esta obra, una "subcesión" de los señores reyes y una creación de Sumos Pontífices y declaración de bulas.

- Tomo segundo en el que se trata la Acienda raíz que este Real Convento tiene en los términos de esta villa de Tordesillas y pueblos de su comarca ${ }^{20}$.

- Tomo tercero de la Hazienda que este Real convento tiene en la ciudad de Soria y lugares de su jurisdicción ${ }^{21}$.

- Tomo cuarto tocante a la Hazienda que el Real convento de Santa Clara desta villa de Tordesillas tiene y goza en la villa de Sepúlbeda, lugares de su jurisdicción y otros e aquel destrito ${ }^{22}$.

- Tomo quinto relativo a censos perpetuos ${ }^{23}$.

De esta forma, nuestro Adicionario al Becerro se denominaría en realidad Adicionario al segundo tomo de la colocación de papeles del Archivo del Real Convento de Santa Clara desta villa de Tordesillas en que se expresa la Acienda que tiene y le pertenece en esta dicha villa y lugares de su jurisdicción y comar$\mathrm{ca}^{24}$. Es decir, que sería el manuscrito que serviría únicamente para actualizar la información de uno de los tomos del Becerro anterior, el segundo concretamente, siendo solo una parte de una obra mayor que se encargaría de actualizar el Becerro por completo. Así lo reflejan algunos "recibos de papeles" localizados en el AHPVA $^{25}$ : registros de entrada y de salida con el que las monjas controlaban toda

18. Rodríguez Guillén, 2011, p. 26.

19. Rodríguez Guillén, 2011, p. 27.

20. AHPVA, Sección Histórica, caja 80/35, capítulo 20. El índice del tomo segundo del Becerro no está titulado de esta forma sino que el título se ha obtenido de forma indirecta. No obstante, un análisis al contenido del índice y al nombre de sus capítulos revelan que efectivamente este segundo tomo del becerro trata de las propiedades del monasterio en Tordesillas y su término.

21. AHPVA, Sección Histórica, caja 80/4, “Índice de los capítulos y sus partidas que se expresan en el tomo tercero...".

22. AHPVA, Sección Histórica, caja 80/5, “Índice de los capítulos que se expresan en el tomo quarto...".

23. Las noticias sobre este quinto tomo pueden verse tanto en el informe realizado en 1776 como en el propio Adicionario donde se da noticia de que, con los censos adicionados, se hará relación en el quinto tomo libro de Vecerro que se formará por lo respectivo a Censos. Véase AHPVA, Sección Histórica, caja 80/28, capítulo 2.

24. AHPVA, Sección Histórica, caja 80/24, capítulo 1, f. 1 r.

25. AHPVA, Sección Histórica, caja 80/6-7. 
la documentación que salía del monasterio para redactar los Adicionarios, asegurándose posteriormente de su correcta reinserción en el convento. En una de las notas de estos recibos, podemos leer:

...se me ha entregado para la continuación de la obra que estoy haciendo de Adiccionarios a los Libros de Becerro, para la buena inteligencia de el Archivo de dicho Real convento y correspondiente al tomo $4^{\circ}$ que trata de la hacienda de Sepúlveda, los instrumentos siguientes ${ }^{26}$.

Y del mismo modo, este Adicionario al segundo tomo del Becerro también aporta datos que nos hacen pensar en un proyecto mayor, en este caso de un trabajo similar para el tomo primero del Becerro. La referencia en concreto se da en el capítulo 12 dedicado a las heredades que el convento tiene en el Cardiel y la Pedraja, aldeas de Portillo; y salinas de sal compás, en Aldeamayor ${ }^{27}$ donde al respecto de dichas salinas se habla de una información contenida en el capítulo 25 del tomo $1^{\circ}$, libro principal del Becerro, y en igual capítulo de su Adicionario. Información que se contiene en el primer tomo por no tratar de hacienda raíz sino de una donación entregada al monasterio en el momento de su fundación, y cuyo capítulo 25 trata efectivamente de la propiedad de las salinas de Aldeamayor, como podemos ver en los índices de ese tomo.

Como vemos, el Adicionario presenta muchos de los elementos que caracterizan a los cartularios tal y como lo define la Comission Intenationale de Diplomatique al reunir las copias íntegras, o extractos de ellas, de una colección de documentos pertenecientes a una institución; si bien dicha colección sería algo atípica pues no compone una colección diplomática en sí misma, sino que actualiza un cartulario anterior. Sin embargo, definirlo únicamente como un cartulario sería una interpretación cuanto menos incompleta e incorrecta pues estaríamos obviando gran parte del contenido presente en este manuscrito.

Ya apuntábamos al comienzo de este análisis que, aunque semejante a esta definición, nuestro objeto de estudio presenta ciertas particularidades que lo diferencian de este tipo de códices diplomáticos y nos llevan a presentarlo como una nueva realidad documental:

- En primer lugar, porque se trata del nombre que le dieron sus creadores, de ahí que en el primer folio del manuscrito pueda leerse: Adicionario al segundo tomo de la colocación de papeles del Archivo del Real Convento de Santa Clara desta villa de Tordesillas ${ }^{28}$.

- En segundo lugar, que su composición no se ha realizado a partir de la organización de un archivo del cual se nutre, sino a partir de la recuperación de un códice diplomático anterior de comienzos del siglo XVIII al que complementa y actualiza pero no sustituye.

26. AHPVA, Sección Histórica, caja 80/6.

27. AHPVA, Sección Histórica, caja 80/37, capítulo 12.

28. AHPVA, Sección Histórica, caja 80/24, capítulo 1. 
- Por último, debido a su contenido que no queda compuesto únicamente por la colección de copias de otros documentos presentes en el archivo de la institución productora. Al margen de esta colección, el Adicionario también se compone de notas y comentarios referidas a estos instrumentos o las heredades a las que se refieren. Notas tanto o más numerosas como los propios instrumentos que se adicionan que informan sobre los motivos de la constante pérdida de propiedades, o incluso dan cuenta sobre el total de pérdidas y las heredades que todavía se conservan, con el fin de actualizar los datos sobre la realidad patrimonial del monasterio. En definitiva, un vasto y rico contenido, que viene a complementar el apartado puramente documental y diplomático de esta obra, y que hace que no podamos definir este manuscrito únicamente como un cartulario, pues también reúne muchas de los elementos característicos de los libros para la administración, tipología documental que ya fue estudiada en profundidad durante las IX Jornadas de la Sociedad Española de Ciencias y Técnicas Historiográficas en el año $2011^{29}$.

\section{ANÁlisis del AdiCIONARIO. Motivos \\ DE SU ORIGEN Y PROCESO DE ELABORACIÓN}

Establecida la singularidad del objeto de estudio, el análisis del Adicionario permitirá responder a una serie de cuestiones sobre el manuscrito: en primer lugar, analizaremos el objeto de estudio con el fin de despejar las dudas acerca de los motivos de su creación; causas que están muy relacionadas con la particular situación que vivía su institución productora, la organización de su archivo y la realidad de su patrimonio a finales del siglo XVIII. En segundo lugar, trataremos de concretar una hipótesis sobre cómo se desarrolló el proceso de elaboración del manuscrito vislumbrando las sombras de un equipo de trabajo encargado de su puesta por escrito; un análisis en el que ha sido fundamental atender a los datos ofrecidos por el análisis codicológico y paleográfico previo del Adicionario.

\subsection{El origen del Adicionario al Becerro}

En el archivo de cualquier institución no es fácil encontrar, aunque los hay, documentos que no sean de archivo, es decir, que no sean testimonio y resultado de un negocio jurídico o administrativo. Al mismo tiempo, cabe entender que cualquier documento creado por una entidad productora debe responder a una necesidad sentida por esa institución, puesto que de otra manera su creación no tendría sentido. De esta forma, para entender el origen del Adicionario tenemos que preguntarnos por la función por la que fue creado, por las necesidades que llevaron a su creación.

29. Munita Loinaz, Lema Pueyo, 2011. 
Para responder a esta pregunta comenzaremos realizando una breve aproximación etimológica pues al contrario que otros términos como Becerro que aluden más a una realidad material; u otras como "libros de cuentas" o "libros de apeos" que aluden al contenido del documento, la palabra Adicionario esconde un sentido más profundo, estrechamente ligado con los motivos que llevaron a su confección. Así, la etimología de esta palabra se relaciona con el vocablo adición: parte, ò porción añadida à otra cosa, y lo mismo que añadidura ${ }^{30}$. Esta palabra procede etimológicamente del término latino additio-additionis, que expresa la añadidura que se hace a algo, normalmente una obra o un escrito anterior. De acuerdo con esta etimología, la función del Adicionario sería la de añadir información a la ya contenida en un códice diplomático anterior, un becerro que, por diversos motivos, había dejado de reflejar la realidad patrimonial del monasterio tal como era en el momento en que se decidió escribir el Adicionario.

$\mathrm{Y}$, en efecto, un primer análisis de contenido permite advertir que en este son constantes las referencias a un códice diplomático anterior cuya información ha quedado vieja, de acuerdo con lo que se apostilla en el nuevo manuscrito. Por ejemplo, este comentario hallado en el capítulo 14, dedicado a los títulos y pertenencias de eredades que el convento tiene en Valladolid, en el que se explica cómo de las veintiuna casas que se inscribieron en el becerro al presente solo posee dos casas [...] Y en quanto a las restantes casas y demás eredades no e podido aberiguar por qué motibo se allan enajenadas y no las posee al presente el convento ${ }^{31}$.

Parece por lo tanto, que efectivamente el objetivo del Adicionario era el de actualizar la información de un Becerro anterior, con el fin de poder seguir percibiendo las rentas y disfrutar de los derechos que el monasterio poseía. Y cabe preguntarse cuáles fueron las causas que provocaron esta situación pues son, al fin y al cabo, los motivos que propiciaron la creación de nuestro objeto de estudio: en primer lugar, la desorganización que venía acusando desde hace un siglo el archivo del cenobio; y en segundo lugar, la problemática composición de su libro Becerro, la cual lo condenaba desde el momento de su creación a la pronta obsolescencia.

Comenzando por el archivo de la institución, el descontrol y desorganización de su contenido ya se venía anunciando por Manuel Queipo de Llano, mayordomo del cenobio desde comienzos de siglo y autor de su último libro Becerro. Pero lejos de ser una situación puntual, testimonios posteriores reflejan como este problema se extendió durante todo el siglo XVIII, provocando que el contenido del archivo dejase de reflejar la verdadera realidad patrimonial, con la consecuente disminución de propiedades y derechos que ello suponía. La prueba más reveladora de esta situación la encontramos en el propio capítulo introductorio del Adicionario donde Antonio Antolínez, como autor del mismo, indicaría que halló faltar muchos de los privilegios y papeles que debía haber en él, lo que se atrivuyó a el poco cuidado que en esto se había tenido; una situación que le

30. Real Academia Española, “voz: Adición”, Diccionario de Autoridades. Vol. I, Madrid, 1762.

31. AHPVA, Sección Histórica, caja 80, capítulo 14. 
llevó a tener que reordenar el archivo antes de comenzar con el trabajo real en el Adicionario $^{32}$.

En segundo lugar, respecto a la composición del libro Becerro, nos encontramos con que este manuscrito se elaboró sin el cuidado de dejar hojas en blanco al final de cada capítulo, provocando que no se pudiera ir actualizando a medida que llegaban nuevos instrumentos al archivo. Una realidad que condenaba a este códice diplomático a quedar obsoleto en pocos años, pues no podía ir ajustando su contenido a la realidad patrimonial y documental cambiante de la institución a la que pertenencia. En realidad, este libro Becerro se encuentra actualmente perdido y no podemos comprobar directamente si sufría de este problema; sin embargo, podemos saberlo de forma indirecta gracias a la descripción que hace del mismo el capítulo introductorio del Adicionario, que advierte como los capítulos del Becerro se siguen unos a otros sin dejar las correspondientes hojas en blanco para anotar los nuevos instrumentos que se fuesen creando, lo que tal vez será la causa de que otros $<$ no se $>$ hayan extractado desde aquel tiempo ${ }^{33}$.

Ahora bien, si tanto la situación patrimonial como del archivo era otra y el Becerro no lo reflejaba, nos surge la pregunta: por qué razón el monasterio de Santa Clara de Tordesillas decidió realizar el Adicionario, salvando de esta manera un códice desactualizado, y no proceder a la escrituración de uno nuevo.

Para responder a esta pregunta debemos detenernos primero en una propuesta acerca de la función de los libros Becerros tardomodernos que ha venido asentándose en los últimos años. Esta teoría, defendida por estudiosos como Carlos Sáez, Concepción Mendo Carmona o Alicia Sánchez Díez ${ }^{34}$, viene a defender que los cartularios de los siglos XVII y XVIII no cumplirían únicamente una función jurídico-administrativa para con su institución productora, sirviendo como forma de presentar copias de sus documentos de archivo en los pleitos con el fin de salvaguardar su patrimonio, al tiempo que se garantizaba la conservación de los originales en las dependencias de la institución. Además de esta función principal, los Becerros, como ocurre con el creado por Queipo, cumplirían con una función archivística que, aunque secundaria, influiría en la forma y composición de estos códices. Y es importante recalcar el calificativo de función secundaria pues pensar que un códice diplomático, incluso del siglo XVIII, tuviera su origen en actuar como instrumento de control podría verse como una conclusión cuanto menos anacrónica y desacertada ${ }^{35}$.

32. AHPVA, Sección Histórica, caja 80/1. En su tesis doctoral, Santiago Rodríguez Guillén atribuye esta introducción al becerro realizado por Queipo de Llano en el primer tercio del siglo XVIII (Rodríguez Guillén, 2011: 28). Sin embargo, las referencias a Antonio Antolínez como autor de este capítulo y la constante alusión al modo de hacer los adicionarios parecen reflejar su pertenencia a esta obra, y no al becerro de Queipo.

33. AHPVA, Sección Histórica, caja 80/1.

34. Véase Sáez 2003-2004, 2005. Mendo Carmona, 2005. Sánchez Díez, 2011.

35. Cruz Herranz, 2016, pp. 189-192. El cartulario como instrumento archivístico no solo sería un error anacrónico sino también una mala interpretación del objeto de estudio pues todos los cartularios realizan un compendio selectivo, y no orgánico, de los documentos del archivo, algo que sería impensable en un verdadero instrumento de control. 


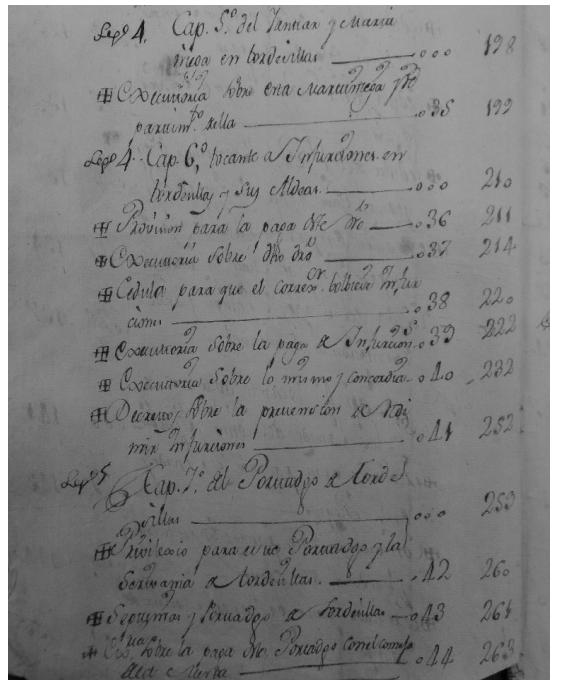

Figura 1. AHPVA, Sección Histórica, caja 80/2-3, Índice de los capítulos y partidas de los expresados en el primero y principal tomo.

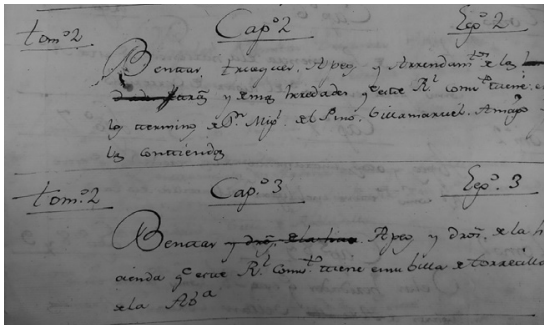

Figura 2. AHPVA, Sección Histórica, caja 80/16, Para el libro $2^{\circ}$ de Acienda de Tordesillas y sus tierras.

En definitiva, estos códices, en principio libros destinados a la gestión patrimonial y administrativa del monasterio, harían a su vez de instrumentos de control, organización y consulta de los documentos originales de la institución, permitiendo su localización física si fuera necesario recurrir a ellos ${ }^{36}$.

Volviendo a nuestro objeto de estudio, no cabe duda de que tanto el propio Becerro principal como el Adicionario posterior, cumplían taxativamente con esta función secundaria hasta el punto de que archivo y códices diplomáticos presentaban el mismo criterio organizativo. Al igual que ambos códices diplomáticos seguían, como ya hemos comentado, una organización toponímica de sus capítulos lo mismo ocurría con su archivo, cuya documentación se organizaba en legajos con el mismo número y orden que los capítulos de los códices. Así podemos verlo tanto en los índices conservados del tomo primero en el que se guarda esta división por capítulos, como en una relación de rotulatas $^{37}$ que llevarían los legajos correspondientes, en este caso, al tomo segundo del Becerro, donde también cada legajo se corresponde con un episodio de dicho tomo.

Esto nos presenta una realidad muy concreta en el archivo de la institución tordesillana. Aunque es verdad que la realidad patrimonial del convento había cambiado, no había ocurrido lo mismo con el archivo, cuya organización intelectual e instalación física seguiría siendo la misma; es decir, si bien la situación patrimonial

36. Cruz Herranz, 2016, pp. 189-192.

37. Según la Real Academia Española, se entiende por rotulata lo mismo que por rótulo: "letrero con que se da a conocer el contenido de otra cosa”. 
necesitaba ser revisada, el continente, o sea el códice diplomático, el Becerro, seguía siendo perfectamente válido para la localización de los documentos en el archivo y su control y por lo tanto para el control de propiedades y rentas. Si el archivo se hubiera reorganizado, el Becerro se habría convertido en un libro inútil. Y no fue así, como se puede observar reflejado en el Adicionario de varias maneras: primero, heredando la realidad organizativa por capítulos de este códice, lo cual refleja que este método seguía siendo uno perfectamente válido para la organización del archivo. Y segundo, mediante las constantes referencias realizadas, al inicio de todos los capítulos, a las páginas del libro Becerro donde se puede encontrar la misma información a la que se va a hacer referencia, lo cual nos habla de un libro Becerro todavía en uso y útil para la localización de la información. Estos son sólo algunos ejemplos de estos hechos: al inicio del capítulo 6 del Adicionario encontramos: En el tomo segundo, libro principal del becerro, capítulo 6 , que trata de las heredades... ${ }^{38}$; o al inicio del capítulo 15: En el capítulo 15, libro principal, tomo segundo del becerro, desde el folio 954 asta el folio 964, uno y otro inclusive, se hace relación de siete eredades ${ }^{39}$...

El resultado de esta realidad es que el visitador Fernando de Rojas no dictaminase la creación de un nuevo cartulario, sino la finalización de un códice diplomático todavía útil pero incompleto al que le faltaba, por un lado, un quinto tomo dedicado a censos; y por otro lado, la agregación de todos los instrumentos que no se habían incluido desde la finalización del trabajo de Queipo de Llano, los cuales se añadirían a la obra con la creación de unos "apéndices" que recibirían finalmente el nombre de Adicionarios $^{40}$.

Siendo este el momento clave para entender el origen de nuestro objeto de estudio, la realidad es que la obra de Antonio Antolínez no se dedicó exclusivamente a esta tarea, sino que este sería únicamente una parte de su contenido definitivo. No hay que olvidar que, como mayordomo y recaudador, Antonio Antolínez tenía a sus espaldas otras muchas funciones relacionadas con la economía y el patrimonio del cenobio tordesillano. El mismo informe de Fernando de Rojas de 1776 da buena cuenta de cuáles eran algunas de estas funciones ${ }^{41}$ : en primer lugar, confirmar que el monasterio goza de las rentas de todas sus propiedades y que estas tienen la cabida indicada en los apeos y demás instrumentos y que no han sufrido alteraciones; es decir, que se sigue poseyendo todo lo que se defiende en sus documentos, aunque estén desactualizados. En segundo lugar, renovar toda esta información para que vuelva a reflejar la realidad patrimonial del cenobio creando para ello todos los instrumentos que fueran necesarios. Finalmente, tras la actualización de esta información hacendística, garantizar la devolución de las propiedades enajenadas o de las que no estén percibiendo rentas con el fin de comunicarlo a la Junta de Hacienda para que tome las medidas necesarias.

38. AHPVA, Sección Histórica, caja 80/40, capítulo 16.

39. AHPVA, Sección Histórica, caja 80, capítulo 15.

40. BNE, ms. 17840, Papeles varios. Tomo IX, Documento 23, f. 154r-v.

41. BNE, ms. 17840, Papeles varios. Tomo IX, Documento 23, ff. 146-156. 
En definitiva, nos encontramos con que el monasterio de Santa Clara de Tordesillas vivía una situación muy concreta en las últimas décadas del siglo XVIII, la cual estaba marcada principalmente por dos necesidades: una, la de formar un libro que complementase su Becerro, pues por su composición codicológica estaba condenado a la obsolescencia desde su nacimiento; y otra, la necesidad de actualizar rápidamente la información sobre su patrimonio, con el fin de conocer su realidad económica cambiante y evitar nuevas pérdidas en el futuro como consecuencia de este desconocimiento. Dos tareas que por ser encomendadas a la misma persona acabarán llevándose a cabo en una misma composición codicológica que recibiría el nombre de Adicionario, un libro que, por ocuparse de ambas cuestiones, acaba heredando características formales tanto de un cartulario, por ser parte de uno al que complementa, como de un libro de la administración pues en último término se encarga de renovar la información económica y patrimonial del cenobio tordesillano.

\subsection{La confección del Adicionario al Becerro}

Para realizar un correcto análisis de este Adicionario, igual de importante resulta comprender los motivos que han llevado a su creación, como el proceso, protagonistas y pautas de trabajo que han llevado a la confección material del mismo. Es por ello que también cabe dedicar un apartado a la materialidad del documento $^{42}$. Aunque a priori pueda parecer que el análisis material de este manuscrito no va a aportar ningún dato de interés a su análisis, al tratarse de un borrador y no de un códice definitivo, la realidad es que conocer las características de la materialidad del Adicionario ha sido fundamental para conocer más detalles sobre su elaboración y el equipo de trabajo implicado en su escrituración.

A grandes rasgos, nuestro objeto de estudio está formado por un conjunto de unos 150 pliegos de papel artesanal separados en un total de veintiún capítulos cosidos individualmente a base de postetas ${ }^{43}$ : un conjunto de pliegos cosidos de una sola batida, empleando en este caso la técnica de diente de perro; a excepción de los capítulos más pequeños que al estar formados por un único pliego no presentan ningún tipo de costura al no ser necesario para mantener su integridad. Esta técnica de encuadernación, aunque de poco valor material, es similar a la técnica hallada en los protocolos notariales contemporáneos de Antonio Antolínez, escribano público de Tordesillas, conservados en el AHPVA. En particular, los protocolos notariales coetáneos realizados entre 1780 y $1790^{44}$ presentan la misma técnica de encuadernado, señalando a Antonio Antolínez no solo como su autor

42. Aunque sería muy interesante detenernos detalladamente en el análisis material de este códice, las exigencias formales de este artículo impiden que podamos hablar de ello en profundidad. El objetivo principal de este artículo es dar a conocer una fuente hallada en el AHPVA hasta ahora desconocida y será en futuros estudios cuando nos detengamos a conocer todos los detalles que esconde la materialidad de este borrador.

43. Gómez Raggio, 1996; Monje Ayala, 1995; Ostos Salcedo, Pardo Rodríguez, Rodríguez Díaz, 1997.

44. AHPVA, Protocolos notariales, cajas 5769-5573. 
intelectual, como ya denotaban los informes de Fernando de Rojas, sino también como su autor material.

Si analizamos esta composición en su conjunto, es evidente cómo el uso de este sistema de postetas refleja la falta de preparación previa de la materia escriptoria del Adicionario antes de proceder a la inserción del texto. Al contrario, la elaboración de este manuscrito se realizó mediante la escritura continuada de pliegos sueltos de modo que una vez terminadas las cuatro caras de un bifolio se comenzaba el siguiente; y finalmente, todos eran reunidos y cosidos en una posteta. Algo por otro lado nada sorprendente si tenemos en cuenta que nos encontramos ante un borrador y no ante el manuscrito definitivo, el cual sí habría requerido de un trabajo previo a la escrituración.

En cualquier caso, una lectura general de la composición codicológica parece no aportar mucha datos más sobre su proceso de creación. No obstante, si realizamos un análisis material más detallado de cada capítulo, observamos que aunque cada uno de ellos forma un todo orgánico, también podrían dividirse en partes más pequeñas creadas con independencia las unas de las otras. La primera de estas divisiones se debe a que varios de los capítulos del códice diplomático, los de mayor extensión, se componen de la unión de más de una posteta. Si agrupamos los datos de la composición del códice en una tabla, teniendo en cuenta la independencia entre cada posteta, obtendríamos lo siguiente:

Tabla 1. Composición codicológica del Adicionario al Becerro.

\begin{tabular}{|c|c|c|c|}
\hline $\begin{array}{l}\mathrm{N}^{\circ} \text { del } \\
\text { capítulo }\end{array}$ & $\begin{array}{l}\mathrm{N}^{\circ} \text { total de } \\
\text { postetas }\end{array}$ & $\begin{array}{l}\mathrm{N}^{\circ} \text { total de } \\
\text { cosidos }\end{array}$ & $\mathrm{N}^{\circ}$ de pliegos/bifolios \\
\hline \multirow[b]{2}{*}{ Capítulo 1} & \multirow[b]{2}{*}{2} & \multirow[b]{2}{*}{3} & Posteta 1.1: 9 bifolios +1 folio suelto +4 bifolios \\
\hline & & & $\begin{array}{l}\text { Posteta 1.2: } 1 \text { bifolio }+1 \text { folio suelto }+5 \text { bifolios }+1 \\
\text { folio suelto }+2 \text { bifolios }\end{array}$ \\
\hline \multirow{4}{*}{ Capítulo 2} & \multirow{4}{*}{4} & \multirow{4}{*}{5} & $\begin{array}{l}\text { Posteta } 2.1: 2 \text { folios sueltos }+3 \text { bifolios }+1 \text { folio suelto }+ \\
3 \text { bifolios }+1 \text { folio suelto }\end{array}$ \\
\hline & & & Posteta 2.2: 5 bifolios \\
\hline & & & $\begin{array}{l}\text { Posteta } 2.3: 1 \text { bifolio }+1 \text { folio suelto }+5 \text { bifolios }+2 \\
\text { folios sueltos }+5 \text { bifolio }\end{array}$ \\
\hline & & & Posteta 2.4: 3 bifolios \\
\hline \multirow{2}{*}{ Capítulo 3} & \multirow{2}{*}{2} & \multirow{2}{*}{2} & Posteta 3.1: 3 bifolios \\
\hline & & & Posteta 3.2: 2 bifolios y un folio suelto \\
\hline Capítulo 4 & N/A & N/A & 1 bifolio \\
\hline Capítulo 5 & \multicolumn{3}{|r|}{ Extraviado } \\
\hline Capítulo 6 & 1 & 1 & Posteta $6.1: 2$ bifolios +1 ternión +2 folios sueltos \\
\hline
\end{tabular}




\begin{tabular}{|c|c|c|c|}
\hline $\begin{array}{l}\mathrm{N}^{\mathrm{o}} \text { del } \\
\text { capítulo }\end{array}$ & $\begin{array}{c}\mathrm{N}^{\mathrm{o}} \text { total de } \\
\text { postetas }\end{array}$ & $\begin{array}{l}\mathrm{N}^{\mathrm{o}} \text { total de } \\
\text { cosidos }\end{array}$ & $\mathrm{N}^{\mathrm{o}}$ de pliegos/bifolios \\
\hline \multirow[b]{2}{*}{ Capítulo 7} & \multirow[b]{2}{*}{2} & \multirow[b]{2}{*}{2} & Posteta 7.1: 1 folio suelto +5 bifolios \\
\hline & & & $\begin{array}{l}\text { Posteta } 7.2: 2 \text { bifolios }+1 \text { folio suelto }+7 \text { bifolio }+ \\
\text { bifolio suelto }\end{array}$ \\
\hline Capítulo 8 & N/A & N/A & 1 folio suelto \\
\hline Capítulo 9 & 1 & 1 & Posteta 9.1: 12 bifolios \\
\hline \multirow[t]{2}{*}{ Capítulo 10} & \multirow[t]{2}{*}{2} & \multirow[t]{2}{*}{2} & $\begin{array}{l}\text { Posteta } 10.1: 1 \text { folio suelto }+2 \text { bifolios }+1 \text { folio suelto } \\
+3 \text { bifolios }+1 \text { folio suelto }+3 \text { bifolios }+1 \text { folio suelto } \\
+1 \text { bifolio }\end{array}$ \\
\hline & & & Posteta 10.2: 5 bifolios \\
\hline \multirow{2}{*}{ Capítulo 11} & \multirow{2}{*}{2} & \multirow{2}{*}{2} & Posteta 11.1: 1 bifolio +1 folio suelto +2 bifolios \\
\hline & & & Posteta 11.2: 7 bifolios \\
\hline Capítulo 12 & N/A & 1 & 1 Ternión \\
\hline Capítulo 13 & N/A & $\mathrm{N} / \mathrm{A}$ & 1 bifolio \\
\hline Capítulo 14 & $\mathrm{~N} / \mathrm{A}$ & N/A & 1 bifolio \\
\hline Capítulo 15 & $\mathrm{~N} / \mathrm{A}$ & $\mathrm{N} / \mathrm{A}$ & 1 folio suelto \\
\hline Capítulo 16 & 1 & 1 & Posteta 16.1: 1 folio suelto +6 bifolios +1 folio suelto \\
\hline Capítulo 17 & 1 & 1 & $\begin{array}{l}\text { Posteta 17.1: } 1 \text { bifolio }+ \text { folio suelto }+9 \text { bifolios }+1 \text { folio } \\
\text { suelto }\end{array}$ \\
\hline Capítulo 18 & N/A & N/A & 1 bifolio \\
\hline Capítulo 19 & 1 & 1 & Posteta 19.1: 3 bifolios \\
\hline Capítulo 20 & 1 & 1 & Posteta 20.1: 2 bifolios \\
\hline Capítulo 21 & 1 & 1 & Posteta 21.1: 6 bifolios +1 folio suelto +2 bifolios \\
\hline
\end{tabular}

Esta práctica de dividir los capítulos más extensos en varias postetas podría responder sencillamente a una decisión estructural; es decir, por la dificultad de abatir más de un número determinado de folios o por asegurar la integridad del cosido, procurando no abordar demasiadas páginas de una sola vez.

No obstante, estos motivos estructurales no parecen ser los correctos ya que no se halla una relación directa entre el número de bifolios utilizados y el número 
de postetas que componen un capítulo. Además, el momento de cambio de una posteta a otra no parece ser aleatorio ya que siempre corresponde con el inicio de una nueva parte del capítulo, denotando esta independencia entre postetas. De esta manera, parece más acertado pensar que cada parte se haya hecho con independencia a las demás y en momentos distintos de modo que a medida que se iba terminando cada posteta esta se incorporaba al capítulo correspondiente mediante nuevos cosidos.

El segundo tipo de división que hallamos en su composición codicológica se encuentra en estas mismas postetas, donde también parece existir cierta autonomía entre cada una de las partes que las componen, entendiendo por estas a los pliegos que reúnen un único instrumento o un conjunto relacionado de ellos. De este modo, cada una de estas divisiones, a las que denominaremos como "apartados", quedarían distinguidas mediante signaturas de cuaderno ocultas en la parte superior del bifolio, las cuales enumeran cada uno de los pliegos de un mismo apartado reiniciándose siempre al comienzo de uno nuevo. Además, el inicio de estos apartados se produce siempre en un nuevo bifolio, marcando aún más la independencia material entre cada uno de ellos. Es esta independencia entre apartados la que explicaría la existencia de folios sueltos presentes en las postetas, y que podemos apreciar en la tabla anterior, pues se localizan siempre al término de uno de estos apartados y son consecuencia de la supresión de la otra parte del bifolio con el fin de evitar grandes espacios en blanco en el manuscrito.

Junto con la supresión de folios, el Adicionario muestra otras prácticas particulares utilizadas para evitar la presencia de espacios en blanco como el uso de grandes aspas o líneas verticales completando los folios; el uso de módulos mayores y renglones más espaciados para ocupar la totalidad de los folios sobrantes, o por el contrario, el uso de módulos e interlineados reducidos para evitar iniciar un pliego nuevo que quedaría incompleto.

Así, la pauta de trabajo que muestra la composición codicológica del Adicionario quedaría resumida de la siguiente manera: la escrituración se realizaría comenzando desde su unidad más pequeña: los "apartados", que se redactarían con independencia los unos de los otros para finalmente ordenarse y coserse posteriormente en postetas, que formarían cada uno de los veintiún capítulos. Esta pauta de trabajo iría dando forma poco a poco al borrador del Adicionario, cuya creación llegará a abarcar un periodo de por lo menos una década, tal y como permiten comprobar las dataciones textuales halladas en el manuscrito y que aluden a los años de $1781^{45}$ y $1791^{46}$. Llama la atención que no se haga referencia a ninguna otra fecha, un dato curioso si lo comparamos con las constantes alusiones a las datas anteriores. Esto plantea la posibilidad de que el trabajo en el Adicionario no fuera uno continuo sino que se viera detenido por factores externos durante al menos gran parte de la década de 1780 .

45. Principales dataciones textuales halladas en AHPVA, Sección Histórica, caja 88/33, capítulo 8.

46. Principales dataciones textuales halladas en AHPVA, Sección Histórica, caja 80/24, capítulo 1. AHPVA, Sección Histórica, caja 80, capítulo 15. AHPVA, Sección Histórica, caja 80/41, capítulo 18. 


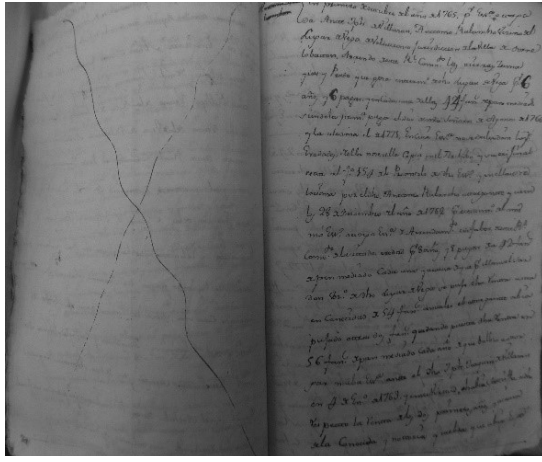

Figura 3. AHPVA, Sección Histórica, caja 80/30, capítulo 21 .

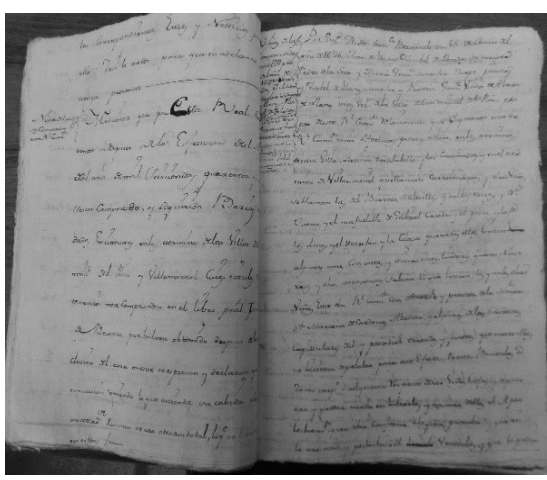

Figura 5. AHPVA, Sección Histórica, caja $80 / 28$, capítulo 2 .

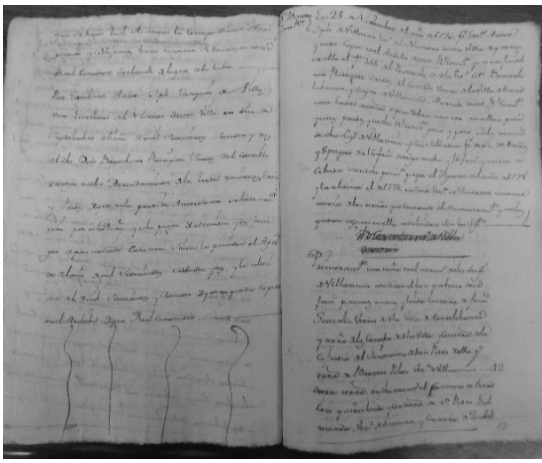

Figura 4. AHPVA, Sección Histórica, caja 80/39, capítulo 17.

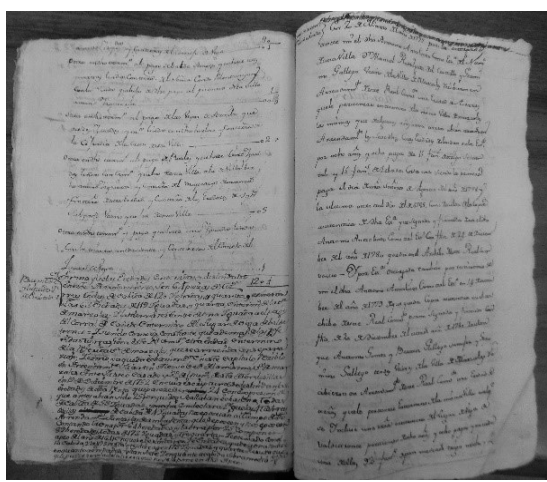

Figura 6 AHPVA, Sección Histórica, caja 80/27, capítulo 10.

A raíz de este hecho, la realización de un análisis paleográfico fue la clave para comprender la inusual extensión en el tiempo en la elaboración de este manuscrito. A rasgos generales, los resultados del análisis paleográfico ${ }^{47}$ han evidenciado la existencia de cuatro manos distintas: la del propio Antonio Antolínez, y tres oficiales pertenecientes a su propia escribanía, como refleja la comparativa entre las manos del Adicionario y la de los protocolos notariales contemporáneos a este. Cuatro escribanos que no formarían un único grupo de trabajo sino dos equipos diferenciados: el primero, que trabajaría en torno a 1781 dando inicio al proceso de escrituración; y un segundo equipo que retomaría la tarea en 1791.

47. Al igual que con el análisis material, resulta poco práctico detenernos ahora en un análisis paleográfico en profundidad, pues el objetivo de este estudio es el de presentar un manuscrito hasta ahora desconocido y resulta imposible realizar un análisis en profundidad de todos sus aspectos. 
Tabla 2. Comparación de las cuatro manos presentes en el Adicionario al Becerro.

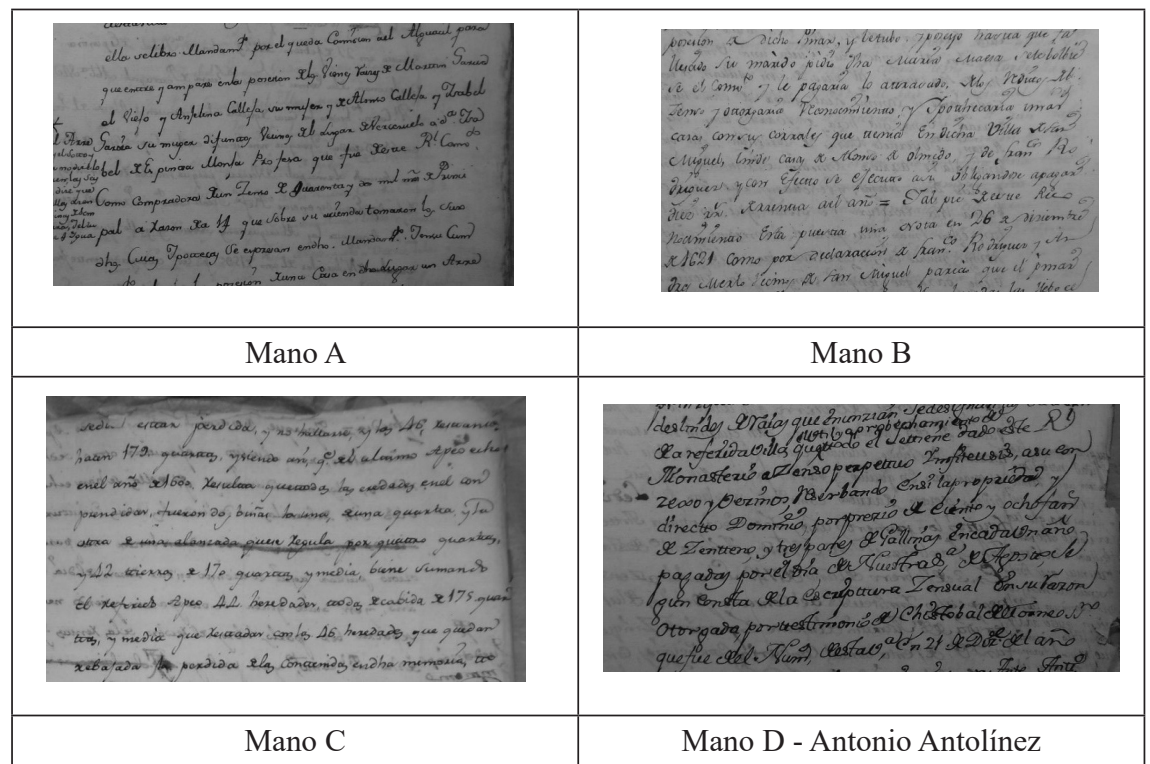

Tabla 3. Relación entre manos del Adicionario y manos de los protocolos notariales

\begin{tabular}{|c|c|}
\hline Adicionario & Protocolos Notariales \\
\hline \multirow[t]{2}{*}{ 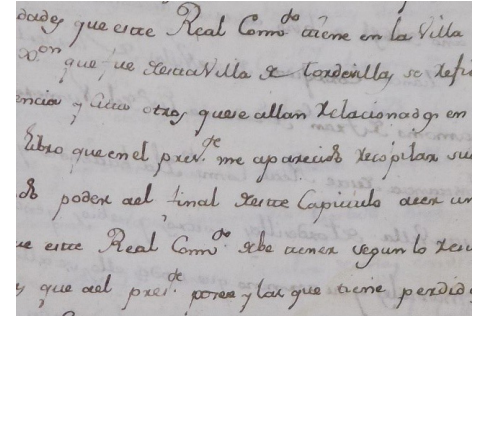 } & 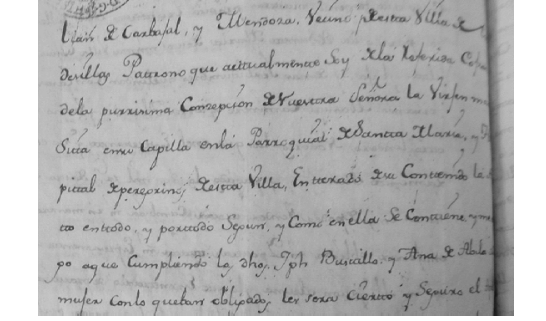 \\
\hline & $\begin{array}{l}\text { AHPVA, Protocolos Notariales, caja } 5570 \text {, } \\
\text { Año } 1784\end{array}$ \\
\hline \multirow[t]{2}{*}{ 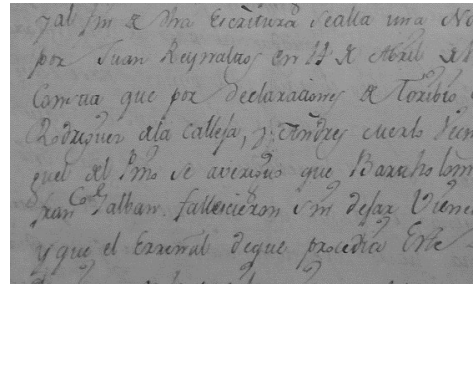 } & 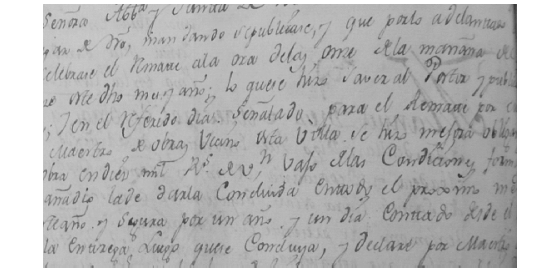 \\
\hline & $\begin{array}{l}\text { AHPVA, Protocolos Notariales, caja } 5570 \text {, } \\
\text { Año } 1783 \text {, f. } 162 \text { r }\end{array}$ \\
\hline
\end{tabular}




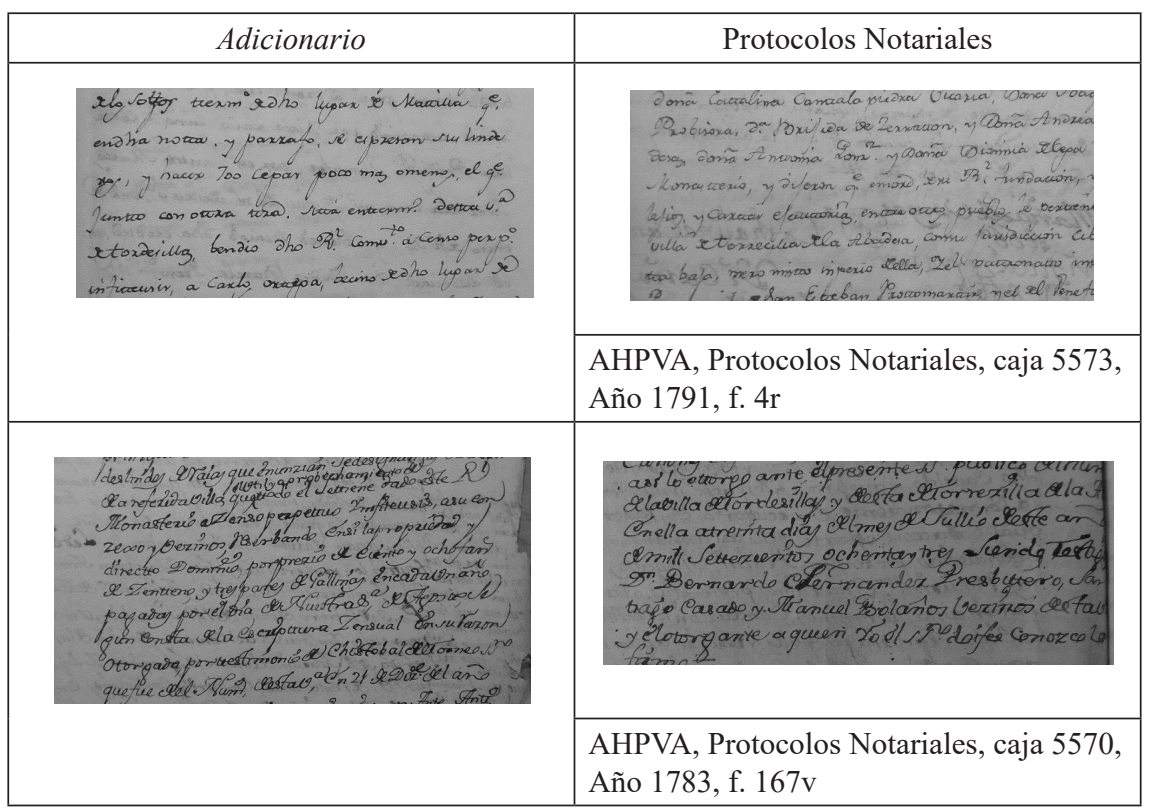

De esta manera, el primer equipo quedaría formado por la Mano A y por la Mano B, escribanos encargados de iniciar la escrituración del borrador a partir de 1781 , tal y como queda reflejado en las dataciones textuales que estos escribanos van realizando a lo largo del manuscrito. Además, también es posible determinar que su trabajo no se prolongó más allá de 1781 si tenemos en cuenta las dataciones indirectas de los documentos con los que se trabajaban. En cambio, aquí comenzaría un periodo de inactividad que se prolongaría hasta 1791, momento en que la Mano C toma la tarea de finalizar el Adicionario, terminando aquellos episodios que habían quedado incompletos o actualizando los que requerían de nueva información. Mientras tanto, la labor de Antonio Antolínez, considerado la mano D, parece ser la de actuar de revisor durante los periodos de actividad de ambos equipos. De este modo, su trabajo se limitaba a la inclusión de notas aclaratorias, la eliminación de partes incorrectas, o la corrección de errores de escritura con el fin de dejar preparado el borrador para su posterior puesta en limpio. Por el contrario, su participación como escribano en la redacción del documento es mínima en comparación con la de sus oficiales, a quienes parece delegar la principal carga de trabajo que suponía la realización material del códice.

Considerando la labor de la mano $\mathrm{C}$, tal parece que la redacción del borrador se dio por concluida en el mismo año de 1791, momento en que se pasaría a elaborar la versión revisada y definitiva del códice diplomático, mediante la rescrituración en limpio de cada uno de sus capítulos. Lamentablemente, ninguno de los catálogos u inventarios realizados para la documentación del monasterio de Santa Clara de Tordesillas da noticia de la existencia de este manuscrito, que al igual que los libros Becerro a los que adicionaba, no parece haber llegado hasta nuestros días. 


\section{ANÁLISIS DEL CONTENIDO}

Finalmente, antes de terminar con el análisis del Adicionario, cabe dedicar unas últimas páginas a analizar el contenido del manuscrito tratando de entender no solo sus características formales sino también el potencial que podría llegar a tener su aprovechamiento y estudio para la comprensión de la realidad patrimonial del monasterio del Santa Clara de Tordesillas a finales del siglo XVIII.

\subsection{La organización administrativo-patrimonial de la información}

Los veintiún capítulos ya mencionados en los que se divide el Adicionario, se encuentran individualizados a partir de un criterio toponímico y patrimonial; es decir, la separación en capítulos de la información del códice responde a una ordenación territorial, de manera que en cada uno de ellos se incluyen las "pertenencias de heredades" del monasterio en un determinado lugar, el cual es indicado en el título de cada apartado con el fin de facilitar la búsqueda de la información: Tordesillas, Vega de Valdetronco, Matilla, etcétera; reuniéndose hasta treinta y siete localidades distintas en las que las monjas clarisas contaban con algún tipo de propiedad y que quedarían ordenadas de la siguiente manera:

- Capítulo 1, de compras y pertenencias de heredades en esta villa de Tordesillas y sus términos.

- Capítulo 2, en que se trata de la hacienda que este real convento tiene en San Miguel del Pino, lugar de su vasallaje, y en Villamarciel, contiguo a él y aldea que fue de Tordesillas.

- Capítulo 3, en que se expresan los derechos de la hacienda que este real convento tiene en su villa de Torrecilla de la Abadesa y su término.

- Capítulo 4, en que se declara las heredades y derechos que el convento tiene en su lugar de San Martín del Monte.

- Capítulo 5, de las heredades que este Real Convento tiene en término de su villa del Pedroso de la Abadesa ${ }^{48}$.

- Capítulo 6, de las heredades que el convento tiene en Verzeruelo, aldea de Tordesillas.

- Capítulo 7, de las heredades que el convento tiene en Matilla, aldea de Tordesillas.

- Capítulo 8, de las heredades que pertenecían al convento en Villán, aldea de Tordesillas.

- Capítulo 9, de las heredades que el convento goza en Bercero y Arenillas, aldeas de Tordesillas, por posesión tomada en virtud de censo contra don Juan de Vega.

48. Es necesario señalar que no se ha encontrado ningún capítulo relativo al Capítulo 5 durante la investigación; todo lo relativo a las propiedades que el monasterio tuvo en Pedroso de la Abadesa se deben a la información obtenida del índice y a la nota ya citada del capítulo 7 relativa a unas propiedades en esta localidad. 
- Capítulo 10, de las heredades que el convento tiene en Marzales, aldea que fue de Tordesillas.

- Capítulo 11, de las heredades que el convento tiene en término de la villa de Velliza, fuera de la jurisdicción de Tordesillas.

- Capítulo 12, de las heredades que el convento tiene en el Cardiel y la Pedraja, aldeas de Portillo, y salinas de sal de compás en Aldeamayor.

- Capítulo 13, de las pertenencias de eredades que el convento tiene en la villa de Medina del Campo y lugares de San Vicente, Valverde, Foncastín, Pollo y la Perdiz, de su jurisdicción y abadía.

- Capítulo 14, de los títulos de pertenencia de heredades que el convento tiene en Valladolid.

- Capítulo 15, de las pertenencias de heredades que el convento tiene en Robladillo.

- Capítulo 16, de las heredades que el convento tiene en Torrelobatón.

- Capítulo 17, que trata de las heredades que el convento tiene en Villasexmir, aldea de Torrelobatón.

- Capítulo 18, de los títulos de pertenencia que el convento tiene de heredades en San Esteban y Cienlabajos, aldea de Arébalo; en Geria, Pozaldez, Alcazarén; lugar de Represa, cerca de Tordehumos; molinos de Olmedo, Villanubla, Ziguñuela y Madrigal.

- Capítulo 19 de las heredades que el convento tiene en San Salvador, por herencia de María de Lara, y en Gallegos.

- Capítulo 20 de las heredades que este Real Convento tiene en término del lugar de Villavieja, jurisdicción de esta villa de Tordesillas.

- Capítulo 21, de las heredades que este real convento tiene en término del lugar de Villavieja, jurisdicción de esta villa de Tordesillas.

No obstante, esta estructuración por capítulos no parece ser una creación pensada ex novo para el Adicionario. Como ya hemos apuntado, la creación de este instrumento a finales del siglo XVIII no estuvo originada por ningún cambio en la organización del archivo del cenobio. Este nuevo manuscrito se pensó como una adición al becerro que contenía las copias de los documentos sueltos del archivo y en el que estos se habían copiado de acuerdo a la organización de este último, que respondía a criterios topográficos y se ajustaba al concepto administrativo-patrimonial del archivo. De ahí que en el nuevo manuscrito, adición al becerro, se imitara la forma en que se organizaba el anterior códice al que complementaba, concretamente a su tomo segundo que es el que trataría de las heredades y pertenencias del monasterio.

Así parece reflejarlo el inicio de todos los capítulos del Adicionario, donde se hace una breve referencia de en qué lugar del libro Becerro se halla la información sobre la que se escribía. Al inicio del capítulo 6 encontramos: En el tomo segundo, libro principal del becerro, capítulo 6 , que trata de las heredades... ${ }^{49}$; al comienzo

49. AHPVA, Sección Histórica, caja 80/31, capítulo 6. 
del capítulo 7: En el capítulo séptimo del dicho libro segundo principal del becerro desde el folio [...] en adelante se trata de las eredades... ${ }^{50}$; al inicio del capítulo 15: En el capítulo 15, libro principal, tomo segundo del becerro, desde el folio 954 asta el folio 964, uno y otro inclusive, se hace relación de siete eredades....

Únicamente dos capítulos parecen no responder a este esquema en la organización interna, tratándose concretamente de los títulos finales del manuscrito, los cuales no están siquiera enumerados de la misma forma que los anteriores. Solo gracias a la consulta de un índice de los capítulos del Adicionario $^{51}$, he podido comprobar que estos se correspondían con los capítulos 20 y 21, relativos a las propiedades del monasterio en las localidades de Villavieja y Vega de Valdetronco respectivamente. En el caso de las posesiones en Vega de Valdetronco, recibidas por herencia de doña Águeda Fernández de Hermosilla, no se agruparon en un apartado propio, sino que estaban incluidas en el capítulo 36 del becerro, como lo señala el propio Antonio Antolínez en este códice. En el caso del título dedicado a Villavieja, lo que ocurre es que el monasterio, al contrario que en otros lugares, no había sufrido una pérdida patrimonial, sino que había adquirido propiedades con posterioridad a la redacción del becerro, por lo que no había noticia de ellas en este último, teniendo que incluir un nuevo apartado para que no se obscurezcan los derechos deste real monasterio ${ }^{52}$.

Por lo que respecta a la disposición de la información en cada uno de los capítulos del Adicionario, esta responde a un mismo criterio. En primer lugar, estos comienzan con una introducción para este capítulo y relación de lo resultante en igual capítulo del libro principal ${ }^{53}$; una presentación del capítulo, más o menos extensa, en las que se presentan las heredades que van a ser incluidas, aludiendo a la parte del Becerro principal donde puede hallarse la misma información, la cual corresponde frecuentemente al mismo título, pues el Adicionario hereda la organización toponímica patrimonial presente en el primer códice. Además, cuando el copista lo consideraba necesario, estas introducciones incluyen también una información general sobre lo que se va a tratar en el resto del capítulo, informando del modo en que se han obtenido las heredades o si se ha dado un gran cambio en su composición. Por reunir todos estos elementos, el capítulo 4 es sin duda el que mejor refleja cómo sería uno de estos apartados introductorios:

En el libro Principal de Becerro tomo primero capitulo 14 y en su Adicionario se relaciona como por la Real fundación deste Real Convento, entre otros efectos, le pertenece la villa de San Martín del Monte y su término sin que en él tenga otra comunidad ni persona particular propiedad de heredad alguna pues todas las comprendidas dentro de los límites del término de la citada villa de San Martín del Monte son propias deste Real Monasterio ${ }^{54}$.

50. AHPVA, Sección Histórica, caja 80/32, capítulo 7.

51. AHPVA, Sección Histórica, caja 80/25, "Índice de los capítulos y sus partidas de lo expresado en este segundo tomo...".

52. AHPVA, Sección Histórica, caja 80/27, capítulo 10.

53. AHPVA, Sección Histórica, caja 80/25.

54. AHPVA, Sección Histórica, caja 80, capítulo 4. 
Tras esta introducción, se pasa a insertar, en forma de extracto, todos los instrumentos que el monasterio posee para testimoniar los derechos de propiedad sobre las heredades mencionadas. Es interesante como todos ellos quedan ordenados siguiendo un criterio cronológico, un método que también parece ser herencia del Becerro de Queipo, como puede verse atendiendo a los ya mencionados índices de sus cuatro tomos conservados en el AHPVA. De este modo, primero se introducirían los instrumentos más antiguos conservados por el cenobio y se continuaría hasta acabar introduciendo los más recientes. Entre todos ellos, destaca la constante aparición de algunas tipologías notariales como compra-ventas, cesiones o trueques; así como también destacan los arrendamientos y los apeos, al ser los que más información ofrecen sobre las propiedades y heredades a las que hacen referencia.

A medida que se van relacionando estos instrumentos van entrando en juego las notas y comentarios al respecto de cada uno de ellos, las cuales suelen encontrarse inmediatamente después del documento al que se refieren con el fin de actualizar la información contenida por los primeros. Es el caso, por ejemplo, de lo observado en el capítulo 7 donde inmediatamente después de hablar de una Benta de un majuelo en favor deste real convento por Vicente de Tapia se incluye una nota informativa que trata sobre haberse bendido este majuelo a Zenso perpetuo a Carlos Ortega ${ }^{55}$. Mientras tanto, otras notas no tienen por objetivo hablar sobre instrumentos extractados sino sobre otros documentos del archivo de importancia para el contenido del Adicionario como son las "notas sobre apeos antiguos" que pueden encontrarse al comienzo de varios capítulos. Estas notas se encargan de resumir el contenido de los apeos incluidos en el Becerro de Queipo con el fin de utilizar su información como punto de partida para la actualización del estado del patrimonio; no obstante, de forma indirecta estas notas reflejan una realidad muy llamativa del contexto del cenobio tordesillano: la inexistencia de apeos nuevos desde la realización del último en 1641, es decir, más de un siglo antes de la realización del Becerro; un hecho que sin duda es uno de los alicientes del desconocimiento del monasterio de su patrimonio, lo cual estaba ocasionando constantes pérdidas.

Pero las notas de mayor interés son las que acompañan a los apeos y arrendamientos adicionados en el manuscrito y tituladas con el nombre de "liquidación y notas": espacios que complementan la información extractada anteriormente ofreciendo un inventario y deslinde de las heredades que lo componen. Un resumen que se enriquece más si cabe con anotaciones en el margen derecho del folio, en las que el escribano va anotando la cantidad de propiedades que suman y la cabida de cada una de ellas de manera que al final del deslinde se termina anotando el total en número y en cabida que suponen todas ellas. Es de destacar este ejemplo presente en el capítulo 6, realizado tras redactar todas las pertenencias que se inspeccionaron en uno de los arrendamientos realizados por el monasterio:

55. AHPVA, Sección Histórica, caja 80/32. Adicionario, capítulo 7. 
Suman y montan las eredades comprendidas en este arrendamiento diez tierras que todas ellas acen veinte fanegas de sembradura, un prado de media fanega y una era de otra media fanega. Y siendo asi que lo que este Real Monasterio debe de tener en término de dicho lugar de Berceruelo según se expresa en la liquidación // y nota puesta en este tomo y capitulo a el becerro, son un arreñal de cabida de una carga de sembradura y onze tierras, todas ellas de cabida de treinta y siete fanegas de sembradura; un zumaque de quatro igadas; una era y un soto. Biene faltando al presente el arreñal y una tierra, y en la cabida de esta y demás tierras en todas ellas faltan diez y siete fanegas, que juntan con las quatro fanegas del arreñal, que también faltan, bienen siendo, uno y otro, veinte y una fanegas de sembradura. Y también falta el zumaque de quatro yguadas, la que se pone por anotación para que sobre su reintegro se practique las correspondientes dilixencias ${ }^{56}$.

Al margen de estos apeos y arrendamientos, algunos capítulos incluyen un "resumen y liquidación final" como colofón del mismo: un apartado muy semejante a los descritos anteriormente pero que se ocupan de contabilizar el número y la extensión de todas las propiedades mencionadas en el capítulo y no únicamente las contenidas por un instrumento; algo que parece ser necesario cuando los resúmenes parciales no son suficientes para describir la realidad de las heredades, bien porque haya habido cambios sustanciales en el patrimonio o porque la mayor variedad de documentos no ha permitido un correcto análisis de su estado. Es el caso del capítulo 7, dedicado a las heredades en Matilla, que por contar con varios apeos, así como numerosos arrendamientos y censos perpetuos, se decide finalizar con un resumen y liquidación final con arreglo a lo resultante de los documentos de que queda expresión en este capitulo, señalando como, salvo que haya habido algún error, el monasterio sigue poseyendo el mismo número de heredades que las indicadas en el apeo de 1502, pero que la cabida tiene un desfase de iguada y media de más, lo que sin duda alguna será porque en unos y otros instrumentos no da medida fija y sí al poco más o menos ${ }^{57}$.

Tanto en unos como en otros, el valor de estos resúmenes es verdaderamente elevado pues sirve para conocer con exactitud la realidad patrimonial que vivía el monasterio en el momento de redacción del Adicionario. Pero además, estos apartados incluyen también constantes referencias a las pertenencias que la institución tordesillana tenía en momentos anteriores, comparando instrumentos de distintas fechas, haciendo que sean una herramienta para conocer el número de propiedades que gozaban en ese momento, y también la cantidad y el volumen de las que habían perdido en los últimos tiempos.

Finalmente, cuando se creía necesario, el capítulo también podía concluir con notas y comentarios al respecto del contenido de lo anterior. Estas, al contrario que las referidas a un instrumento en concreto, tendrían un carácter más general y se encargarían de aclarar algún detalle sobre el contenido del capítulo que se debiera tener en cuenta. Por ejemplo, y de nuevo en el capítulo 7 sobre las propiedades

56. AHPVA, Sección Histórica, caja 80/31, capítulo 6.

57. AHPVA, Sección Histórica, caja 80/32. Adicionario, capítulo 7. 
en Matilla, este finaliza con una nota de que algunas de estas tierras que se dice estar en término del lugar de Matilla existen en término de la villa del pedroso de la Abadesa; una nota que se añade al final del capítulo con el fin de que haia la debida claridad y evitar confusiones en lo subcesivo ${ }^{58}$.

\subsection{Santa Clara de Tordesillas a través de su Adicionario}

La información que proporciona este Adicionario sobre el monasterio de Santa Clara de Tordesillas amplía, no cabe duda, el conocimiento que tenemos de la institución en el momento en que el manuscrito se escribió. Podría pensarse, $a$ priori, complicado que un único documento permita percibir la realidad patrimonial de una institución, pero cuando se analiza la fuente, se advierte la amplísima y riquísima información que ofrece sobre la situación patrimonial y archivística del cenobio tordesillano, que retrotrae además a las centurias bajomedievales y modernas ${ }^{59}$.

La elaboración de un códice diplomático de estas características a finales del siglo XVIII permite deducir, como hemos afirmado, que el archivo del monasterio estaba perfectamente organizado y ordenado, de acuerdo a unos criterios que se consideraron válidos. Tan válidos que las referencias en el Adicionario son constantes, prueba de su vigencia. Es por este motivo que los encargados del archivo decidieron elaborar este códice diplomático en lugar de un nuevo becerro, precisamente porque la organización era válida, y ni se sintió la necesidad de cambiarla ni se entendió necesaria la redacción de un nuevo códice. De ahí que el Adicionario herede la estructura (deudora de un concepto administrativo-patrimonial del archivo) del propio becerro, basada en una clasificación toponímica de los documentos.

Sin duda, esa organización toponímica responde a un concepto patrimonial del archivo, en el que la conservación de la documentación se explica fundamentalmente por su función testimonial y probatoria de los derechos que esta confería. De esta manera, a la hora de recuperar la información sobre la posesión de una propiedad, resultaba mucho más sencillo acceder a ella si estaba organizada según criterios toponímicos, es decir, que todos los documentos relativos a propiedades de un determinado lugar estuvieran reunidos en un mismo espacio del archivo y en un capítulo concreto del libro.

Por lo que atañe a la información que nos proporciona el Adicionario al becerro para el conocimiento del estado de las pertenencias del monasterio, este documento, como fuente, permite contabilizar las posesiones del cenobio de dos formas distintas: en primer lugar, mediante el número total de tierras. Segundo, mediante la cabida total de las propiedades expresadas en yugadas. Sin embargo,

58. AHPVA, Sección Histórica, caja 80/32, capítulo 7.

59. Para conocer la realidad en su contexto, se hace precisa la utilización de otras fuentes. No es propósito de este artículo el análisis de la realidad ajena a la propia institución, pero pueden consultarse con intención de acercarse a ella las Respuestas Generales del Catastro del marqués de la Ensenada, que para el caso de Tordesillas han sido realizadas en Camarero Bullón, 1993. 
el valor del Adicionario no reside únicamente en que ofrece una visión detallada del patrimonio monástico a finales del siglo XVIII, sino en que además ofrece una visión comparada con las posesiones que tenía el monasterio en el momento de la realización del anterior becerro, y que en muchos casos se retrotrae incluso hasta el periodo fundacional del cenobio. Por este motivo, el Adicionario se muestra como un documento excelente porque ofrece una doble imagen (sincrónica y diacrónica) del patrimonio de la institución.

El análisis del Adicionario nos permite responder a dos preguntas: en primer lugar, si puede o no confirmarse que la situación patrimonial del monasterio había cambiado en los años anteriores a la realización del códice y desde la escrituración del Becerro; y, en segundo lugar: responder también a la pregunta de cómo y en qué medida se produjeron esos cambios. Un estudio que este Adicionario permite realizar además de una manera más bien sencilla, pues toda esta información se encuentra concentrada en los ya citados "resúmenes y liquidaciones de heredades" localizados en cada uno de los capítulos. De este modo, si extraemos la información sobre el patrimonio y sus variaciones contenida en estos apartados e incluimos los resultados en una tabla, el resultado que obtenemos es el siguiente (tabla 4).

Los datos ofrecidos en la tabla sirven para confirmar que el balance de los cambios que había experimentado el monasterio fueron negativos, con una evidente pérdida de pertenencias y derechos patrimoniales, como ocurre en los ya mencionados casos de Robladillo y Villán, donde las clarisas perdieron todas las propiedades que un día poseyeron; o Valladolid, donde llegó a perder la posesión de hasta diecinueve casas.

Resultaría interesante conocer los motivos que ocasionaron estas reiteradas enajenaciones de las propiedades del convento. Una vez más, el Adicionario al becerro vuelve a darnos interesantes datos sobre esta cuestión, reflejando el enorme descuido con que el cenobio trató la información y la documentación referente al patrimonio del monasterio. En el capítulo 9, relativo a las pertenencias en Bercero y Arenillas, se informa del aumento de las propiedades, aunque el total de su capacidad había menguado, ante lo cual el escribano anotó:

Y no queda duda que la diferencia que resulta de unos a otros arrendamientos nace del poco cuidado que se a tenido en haberiguar si los deslindes que se han dado por los renteros al tienpo de hacer sus escripturas de arrendamientos estaban o no arreglados a lo que debía de ser, por lo que en lo subcesibo se tendrá maior cuidado en ello ${ }^{60}$.

60. AHPVA, Sección Histórica, caja 80/34, capítulo 9. 
Tabla 4. Comparativa entre las propiedades reflejadas en el adicionario y las reflejadas en instrumentos anteriores.

\begin{tabular}{|c|c|c|c|c|c|}
\hline $\begin{array}{l}\text { Lugares de } \\
\text { procedencia } \\
\text { de las } \\
\text { heredades. }\end{array}$ & $\begin{array}{l}\text { Patrimonio } \\
\text { total reflejado } \\
\text { en los } \\
\text { instrumentos } \\
\text { anteriores } \\
\text { ( } \mathrm{n}^{\circ} \mathrm{de} \\
\text { pertenencias) }\end{array}$ & $\begin{array}{l}\text { Patrimonio total reflejado } \\
\text { en los instrumentos } \\
\text { anteriores (cabida total) }\end{array}$ & \multicolumn{2}{|c|}{$\begin{array}{l}\text { Patrimonio total reflejado } \\
\text { en el adicionario }\left(\mathrm{n}^{\circ} \text { de }\right. \\
\text { pertenencias })\end{array}$} & $\begin{array}{l}\text { Patrimonio total } \\
\text { reflejado en el } \\
\text { adicionario (cabida } \\
{\text { total })^{61}}^{6}\end{array}$ \\
\hline \multirow{5}{*}{ Tordesillas } & \multirow{4}{*}{ En el campo } & \multirow{4}{*}{$\begin{array}{l}\text { Se desconoce tanto el } \\
\text { número de propiedades } \\
\text { como la cabida total que } \\
\text { el monasterio poseía } \\
\text { en Tordesillas antes } \\
\text { de la realización del } \\
\text { Adicionario debido a que } \\
\text { no consta en sus folios. }\end{array}$} & \multirow{4}{*}{ En el campo } & 21 tierras & $\begin{array}{l}185 \text { yugadas y } 231 \\
\text { estadales }\end{array}$ \\
\hline & & & & 1 Soto & 91 estadales \\
\hline & & & & 3 huertas & $\begin{array}{l}5 \text { yugadas y } 66 \\
\text { estadales }\end{array}$ \\
\hline & & & & $\begin{array}{l}1 \text { ribera de } \\
\text { arboles }\end{array}$ & 78 yugadas \\
\hline & En la villa & 24 casas & \multicolumn{2}{|l|}{ En la villa } & 30 casas \\
\hline \multirow{2}{*}{$\begin{array}{l}\text { San Miguel } \\
\text { del Pino y } \\
\text { Villamarciel }\end{array}$} & 513 heredades & $\begin{array}{l}764 \text { yugadas, tres cuartas } \\
\text { y } 82 \text { estadales. }\end{array}$ & \multirow{2}{*}{\multicolumn{2}{|c|}{513 heredades }} & \multirow{2}{*}{$\begin{array}{l}764 \text { yugadas, } \\
\text { tres cuartas y } 82 \\
\text { estadales. }\end{array}$} \\
\hline & 11 viñas & 35 yugadas & & & \\
\hline $\begin{array}{l}\text { Torrecilla de } \\
\text { la Abadesa }\end{array}$ & 17 tierras & 29 yugadas & \multicolumn{2}{|l|}{17 tierras } & 29 yugadas \\
\hline $\begin{array}{l}\text { San Martín } \\
\text { del Monte }\end{array}$ & \multicolumn{5}{|c|}{$\begin{array}{l}\text { Todas las (propiedades) comprendidas dentro de los limites del término de la citada villa de San } \\
\text { Martín del Monte son propiedad del Real Monasterio [...] a censo perpetuo enfiteusis por precio } \\
\text { de ciento y ocho fanegas de centeno y tres partes de gallinas pagadas cada día de Nuestra Señora } \\
\text { de Agosto }{ }^{62} \text {. }\end{array}$} \\
\hline $\begin{array}{l}\text { Pedroso de } \\
\text { la Abadesa }\end{array}$ & \multicolumn{2}{|c|}{ Despoblado hasta $1786^{63}$} & \multicolumn{2}{|l|}{8 tierras } & $\begin{array}{l}20 \text { yugadas y } 221 \\
\text { estadales }\end{array}$ \\
\hline \multirow{4}{*}{ Verzeruelo } & 1 arreñal & Una carga de sembradura & & & \\
\hline & 11 tierras & 37 fanegas & \multicolumn{2}{|l|}{10 tierras } & 20 fanegas \\
\hline & Un zumaque & 4 yugadas & & & \\
\hline & Una era & & \multicolumn{2}{|l|}{ Una era } & \\
\hline Matilla & 73 tierras & $\begin{array}{l}101 \text { yugadas, una cuarta y } \\
13 \text { estadales }\end{array}$ & \multicolumn{2}{|l|}{65 tierras } & $\begin{array}{l}148 \text { yugadas y } 111 \\
\text { estadales }\end{array}$ \\
\hline Villán & \multicolumn{2}{|c|}{$\begin{array}{l}\text { sesenta yugadas de tierras de pan llevar } \\
\text { para labranza de un par de bueyes año } \\
\text { y vez }\end{array}$} & & & \\
\hline $\begin{array}{l}\text { Bercero y } \\
\text { Arenillas }\end{array}$ & 52 heredades & $\begin{array}{l}62 \text { fanegas y } 16 \\
\text { celemines }\end{array}$ & \multicolumn{2}{|l|}{48 heredades } & $\begin{array}{l}53 \text { fanegas y } 9 \\
\text { celemines. }\end{array}$ \\
\hline Marzales & 97 heredades & 178 yugadas & \multicolumn{2}{|l|}{86 heredades } & 156 yugadas \\
\hline Velliza & 33 heredades & $\begin{array}{l}117 \text { yugadas y media y } 11 \\
\text { estadales }\end{array}$ & \multicolumn{2}{|l|}{33 heredades } & $\begin{array}{l}127 \text { yugadas y } 11 \\
\text { estadales. }\end{array}$ \\
\hline $\begin{array}{l}\text { Cardiel y la } \\
\text { Pedraja }\end{array}$ & 44 heredades & 175 cuartas y media & \multicolumn{2}{|l|}{46 heredades } & 179 cuartas \\
\hline
\end{tabular}

61. La medida utilizada en el Adicionario para el cálculo de la cabida es la "yugada de Tordesillas", que equivale a 266 estadales.

62. AHPVA, Sección Histórica, caja 80, capítulo 4.

63. Archivo General de Palacio, Reales Patronatos, Convento de Santa Clara de Tordesillas. caja 19, Expediente 15. 


\begin{tabular}{|c|c|c|c|c|}
\hline $\begin{array}{l}\text { Lugares de } \\
\text { procedencia } \\
\text { de las } \\
\text { heredades. }\end{array}$ & $\begin{array}{l}\text { Patrimonio } \\
\text { total reflejado } \\
\text { en los } \\
\text { instrumentos } \\
\text { anteriores } \\
\text { ( } \mathrm{n}^{\circ} \mathrm{de} \\
\text { pertenencias) }\end{array}$ & $\begin{array}{l}\text { Patrimonio total reflejado } \\
\text { en los instrumentos } \\
\text { anteriores (cabida total) }\end{array}$ & $\begin{array}{c}\text { Patrimonio total reflejado } \\
\text { en el adicionario }\left(\mathrm{n}^{\circ} \text { de }\right. \\
\text { pertenencias })\end{array}$ & $\begin{array}{c}\text { Patrimonio total } \\
\text { reflejado en el } \\
\text { adicionario (cabida } \\
\text { total) }^{61}\end{array}$ \\
\hline $\begin{array}{l}\text { Medina del } \\
\text { Campo, San } \\
\text { Vicente, } \\
\text { Valverde, } \\
\text { Foncastín, } \\
\text { Pollos y la } \\
\text { Perdiz. }\end{array}$ & \multicolumn{2}{|c|}{$\begin{array}{l}\text { En el libro principal, tomo segundo } \\
\text { del Becerro [...], se relacionan varios } \\
\text { títulos de pertenencia de casas, tierras, } \\
\text { y otras eredades que según ellos parece } \\
\text { pertenecian a este Real Convento }{ }^{64} \text {. }\end{array}$} & \multicolumn{2}{|c|}{$\begin{array}{l}\text { Una casa en Medina que hace esquina a la plaza } \\
\text { maior y calle de la plaza della }{ }^{65} \text {. }\end{array}$} \\
\hline Valladolid & $\begin{array}{l}21 \text { casas y } \\
\text { otros títulos de } \\
\text { pertenencia. }\end{array}$ & & 2 casas. & \\
\hline Robladillo & \multicolumn{2}{|c|}{$\begin{array}{l}\text { se relacionan siete escrituras de venta de } \\
\text { diferentes tierras, prados, viñas y } \operatorname{casas}^{66} .\end{array}$} & & \\
\hline Torrelobatón & 33 tierras & 123 fanegas y media & 32 tierras & 121 fanegas. \\
\hline \multirow{3}{*}{ Villasexmir } & 30 tierras & 67 fanegas y tres cuartas & 27 tierras & $\begin{array}{l}79 \text { fanegas y tres } \\
\text { celemines }\end{array}$ \\
\hline & Una era & Una fanega y cuarta & Una era & Media fanega \\
\hline & 5 prados & 6 fanegas & 4 prados & 8 fanegas y media \\
\hline $\begin{array}{l}\text { San Esteban, } \\
\text { Cienlabajos, } \\
\text { Geria, } \\
\text { Pozaldez, } \\
\text { Alcazarén, } \\
\text { Molinos de } \\
\text { Olmedo, } \\
\text { Villanubla, } \\
\text { Ziguñuela, y } \\
\text { Madrigal. }\end{array}$ & \multicolumn{2}{|c|}{$\begin{array}{l}\text { Se hace relación de varios títulos de } \\
\text { pertenencia que este Real Convento tiene }{ }^{67} \text {. }\end{array}$} & $\begin{array}{l}\text { Dos tierras localizadas en } \\
\text { Geria. }\end{array}$ & $\begin{array}{l}\text { Una yugada y } \\
\text { media. }\end{array}$ \\
\hline $\begin{array}{l}\text { San } \\
\text { Salvador y } \\
\text { Gallegos }\end{array}$ & 12 tierras & 14 yugadas & 11 propiedades & 13 yugadas y cuarta \\
\hline Villavieja & & & 7 tierras & 14 yugadas y media. \\
\hline \multirow{3}{*}{$\begin{array}{l}\text { Vega de } \\
\text { Valdetronco }\end{array}$} & 10 zumaques & 20 yugadas & 10 zumaques & 13 yugadas. \\
\hline & Un prado & Una yugada y media. & Un prado & Una yugada. \\
\hline & Una tierra & 5 cuartas & Una tierra & 3 cuartas. \\
\hline
\end{tabular}

Y de nuevo en el capítulo 17, se vuelve a hacer hincapié en el problema de los deslindes:

viene faltando de yncluir en el deslinde deste último arrendamiento tres tierras y un prado, y en la cabida de todo la de 24 fanegas de sembradura, cuia falta puede atribuirse a la omisión que habido (sic) en hacer apeos generales y poco cuidado

64. AHPVA, Sección Histórica, caja 80/38, capítulo 13.

65. AHPVA, Sección Histórica, caja 80/38, capítulo 13.

66. AHPVA, Sección Histórica, caja 80, capítulo 15.

67. AHPVA, Sección Histórica, caja 80/41, capítulo 18. 
en cotejar los deslindes que los renteros an dado al tienpo de hacer sus arrendamientos [...] Por lo que será muy combeniente que en lo subcesibo se hagan apeos generales para reintegrar al convento / de lo que le falta y que siguiéndose en hacer los arrendamientos con deslinde formal se conserbe la perpetuidad de las eredades ${ }^{68}$.

\section{CONCLUSIONES}

La primera de las conclusiones deriva de la singularidad del manuscrito con el que hemos trabajado. El descubrimiento de este Adicionario representa, en primer lugar, una nueva realidad documental que es necesario considerar como tal, pero también representa una nueva forma de actuar no conocida por los escribanos bajomodernos, quienes decidieron salvar un becerro a través de apostillas en lugar de desecharlo y realizar uno nuevo, como se pensaba hasta la actualidad que siempre se hacía.

La segunda conclusión es reconocer como una fuente extraordinaria de información al Adicionario, puesto que permite reconocer que el archivo de este convento de clarisas estaba, a finales del siglo XVIII, organizado de acuerdo a un concepto administrativo-patrimonial, en el que no importaba la conservación de la documentación por su valor histórico tanto como por su valor jurídico y patrimonial, que garantizaba la conservación de una serie de propiedades, derechos y rentas. Tal concepción da lugar a una estructura del manuscrito basada en una organización toponímica por capítulos, que reproduce la estructura del becerro al que complementa y la del propio archivo monástico.

El Adicionario permite además y sobre todo conocer la situación patrimonial del monasterio en el momento de su realización y cómo esta realidad había cambiado respecto al momento de escrituración del becerro anterior, que había quedado por ello relativamente desactualizado. Esa realidad cambiante supone una transformación del patrimonio en sentido negativo para las clarisas, de manera que el Adicionario refiere principalmente pérdidas tanto en el número de pertenencias como en la capacidad total de las propiedades del cenobio.

\section{BIBLIOGRAFÍA CITADA}

Almagro García, Antonio (2005), "El palacio de Pedro I en Tordesillas, realidad e hipótesis", Reales Sitios: Revista del Patrimonio Nacional, 163, pp. 2-13.

Bahr, Cecilia (1996), "El Convento de Santa Clara y la reactivación económica de la región de Tordesillas luego de la crisis de mediados del siglo XIV", Estudios de historia de España, 5, pp. 43-66.

68. AHPVA, Sección Histórica, caja 80/39, capítulo 17. 
Camarero Bullón, Concepción; Varela Bueno, Consuelo; Gil Fernández, Juan (1994), Tordesillas en 1751 según las respuestas generales del Catastro de Ensenada.

Cárcel Ortí, María Milagros (ed.) (1997), Vocabulaire Internationale de la Diplomatique, Valencia.

Castro y Castro, Manuel de (1973), Manuscritos franciscanos de la Biblioteca Nacional de Madrid, Madrid. (Se hace referencia al manuscrito 17840 "Papeles Varios. Tomo IX”. Proc. Colección Pascual Gayangos: "Auto de la abadesa de Santa Clara de Tordesllas ante Antonio Antolínez, por el que se renuevan los estatutos y de más compromisos de la carta de fundación de dicho monasterio. Tordesillas, 3 de septiembre de 1776").

Castro, Jonás (1981), Colección diplomática de Tordesillas, 909-1474, Valladolid.

Castro, Manuel de (1989), "Monasterios hispánicos de clarisas desde el siglo XIII al XVI", Archivo Ibero-Americano, 49, pp. 79-122.

Chacón Gómez-Monedero, Francisco Antonio (2006) "El dominico fray Vicente Velázquez de Figueroa en los planes archivísticos del Cabildo conquense", Archivo Dominicano: Anuario 27, pp. 75-116.

Cruz Herranz, Luis Miguel de la (2016), "El archivo monástico. Entre la gestión de su administración y la gestión de su memoria histórica", Baldaqui Escandell, Ramón (ed.), Lugares de Escritura: el monasterio, Alicante, pp. 177-230.

Fernández Flórez, José Antonio (1993), "La Congregación benedictina de Valladolid en el siglo XVIII”, Gimeno Blay, Francisco (ed.) Erudición y discurso histórico: las instituciones europeas (s. XVIII-XIX), Valencia, pp. 101-128.

García Frías-Checa, Carmen (1992), Guía del Real Monasterio de Santa Clara de Tordesillas, Madrid.

Gimeno Blay, Francisco (1986), Las llamadas ciencias auxiliares de la historia, ¿errónea interpretación?, Consideraciones sobre el método de investigación en paleografía, Zaragoza.

Gómez Raggio, Francisco (1996), El Libro de la encuadernación, Madrid.

González Cristóbal, Margarita (1987), Monasterio de Santa Clara de Tordesillas: Inventarios Documentales [por Margarita González Cristóbal], Madrid.

González Herrera, Eusebio (1965), El Real Monasterio de Santa Clara de Tordesillas, Barcelona.

Keller, Adrián (2007), "El "Becerro" vices gerens: con el ternero a la magistratura”, María del Val González de la Peña (coord.), Estudios en memoria del profesor Dr. Carlos Sáez. Homenaje, Universidad de Alcalá de Henares, pp. 95-108.

Martín Postigo, María de la Soterraña (1982), Tras las huellas de fray Vicente Velázquez de Figueroa, Valladolid.

Mendo Carmona, Concepción (2002), "Los tumbos medievales desde la perspectiva archivística", Javier de Santiago Fernández, José María de Francisco Olmos (eds.), I Jornadas Cientifica sobre documentación jurídico-administrativa, económica financiera y judicial en el reino castellano leonés (s. X-XIII), Universidad Complutense de Madrid, pp. 165-189. 
Mendo Carmona, Concepción (2005), "El cartulario como instrumento archivístico", Revista de Historia de la Cultura Escrita 15, pp. 119-137.

Monje Ayala, Mariano (1995), El arte de la encuadernación, Madrid.

Munita Loinaz, José Antonio y Lema Pueyo, José Ángel (coords.) (2012), La escritura de la memoria: libros para la administración. IX Jornadas de la Sociedad Española de Ciencias y Técnicas Historiográficas (Vitoria-Gasteiz, 23 y 24 de junio de 2011), Bilbao.

Ostos Salcedo, Pilar; Pardo Rodríguez, María Luisa; Rodríguez Díaz, Elena (1997), Vocabulario de Codicología, Madrid.

Rodríguez Díaz, Elena; García Martínez, Antonio Claret (2011), La escritura de la memoria: los cartularios, Universidad de Huelva.

Rodríguez Guillén, Santiago (2011), El Monasterio de Santa María la Real de Tordesillas (1363-1509), Universidad de Alcalá de Henares, (Tesis Doctoral).

Ruiz Asencio, José Manuel (1972), "Voz: Cartulario", Quintín Aldea Vaquero, Tomás Marín Martínez \& José Vives Gatell (dirs.), Diccionario de Historia Eclesiástica de España, Madrid, Consejo Superior de Investigaciones Científicas, vol. I, pp. 368-370.

Sáez, Carlos (2003-2004), "Códices diplomáticos y conservación documental", Acta Medievalia et Archeologica 25, pp. 831-848.

Sáez, Carlos (2005), “Origen y función de los cartularios hispanos”, Anuario del Centro de Estudios Históricos "Prof. Carlos S. A. Segreti 5, pp. 37-48.

Sánchez Díez, Alicia (2011), "Los códices diplomáticos llamados becerros. Notas sobre su denominación, estructura y función”, Salamanca López, Manuel (dir.), La materialidad escrita: nuevos enfoques para su investigación, Oviedo.

Suárez González, Ana (2016), "Libros, memoria y archivos: cartularios monásticos del Noreste peninsular (siglos XII y XIII)", Ramón Baldaquí Escandell (coord.), Lugares de Escritura: el monasterio, Universidad de Alicante, pp. 469-476. 